traces of whitish subdorsal and lateral lines, the posterior parts of segments annulate and grayer; subventral fold pale with black dashes above anteriorly on the segments; venter with several irregular, geminate, crinkled, black lines, subtesselate blotched posteriorly on the segments ; whitish orange shading at the spiracle especially on joints 5 and 6. Feet gray; spiracles black rimmed; setae normal, short, ia to ib separate, iv stigmatal posterior, vii of three in a triangle subventrally, not much scattered. Cocoon a fairly close web of brown silk.

Food plant. The larvae were fed on wild cherry.

Eggs from a $q$ taken at Pine Grove, Colorado. Eggs July roth, mature larvae August Ioth, the moth again August 2oth.

\title{
A NEW CATOLACCUS ON SITOTROGA CEREALELLA OLIV.
}

BY William H. AShmead, Washington, D. C.

The following new Pteromalid was bred at the U. S. Department of Agriculture from infested specimens of Sitotroga cerealella Oliv., taken by Mr. Dunwoody, in Philadelphia.

Catolaccus cerealellae, sp. nov.

‥- Length 2 to $2.5 \mathrm{~mm}$. Metallic bronze green, closely punctate and sparsely pubescent. The abdomen is conic-ovate and usually but not always a little longer than the head and thorax united the two or three basal segments tinged with cupreous, the segments subequal in length with some very delicate transverse aciculations.

The legs are metallic green, the knees, tibiae and tarsi, except the last joint, the scape of the antennae and the labial palpi being honeyyellow; the maxillary palpi and the rest of the antennae are dark fuscous; the flagellum is very slightly and gradually thickened towards apex, the ring-joints annular, the first joint of funicle being usually a little long- er than the pedicel or as long, the following joints very gradually shortening to the club, the last being obtrapezoidal in outline, a little wider at base than at apex; the joints of the club, or at least the first two, are wider than long. The head is transverse, wider than the thorax or about $3 \frac{1}{2}$ times as wide as thick antero-posteriorly, thinnest at the middle. Wings hyaline, the veins light-brown or brownish yellow. The metathorax is impressed on each side posteriorly with usually a short delicate median carina on the middle lobe at base.

The male measures scarcely $2 \mathrm{~mm}$. in length, bronzed black, the flagellum being filiform and densely hairy, while the abdomen has a yellow median spot basally and is oblong-oval, not pointed at apex.

Type-Cat. No. 6115, U. S. N. M.

Hab.- Philadelphia.

Host.-Lepid. Sitotroga cerealella Oliv. 



Submit your manuscripts at

http://www.hindawi.com
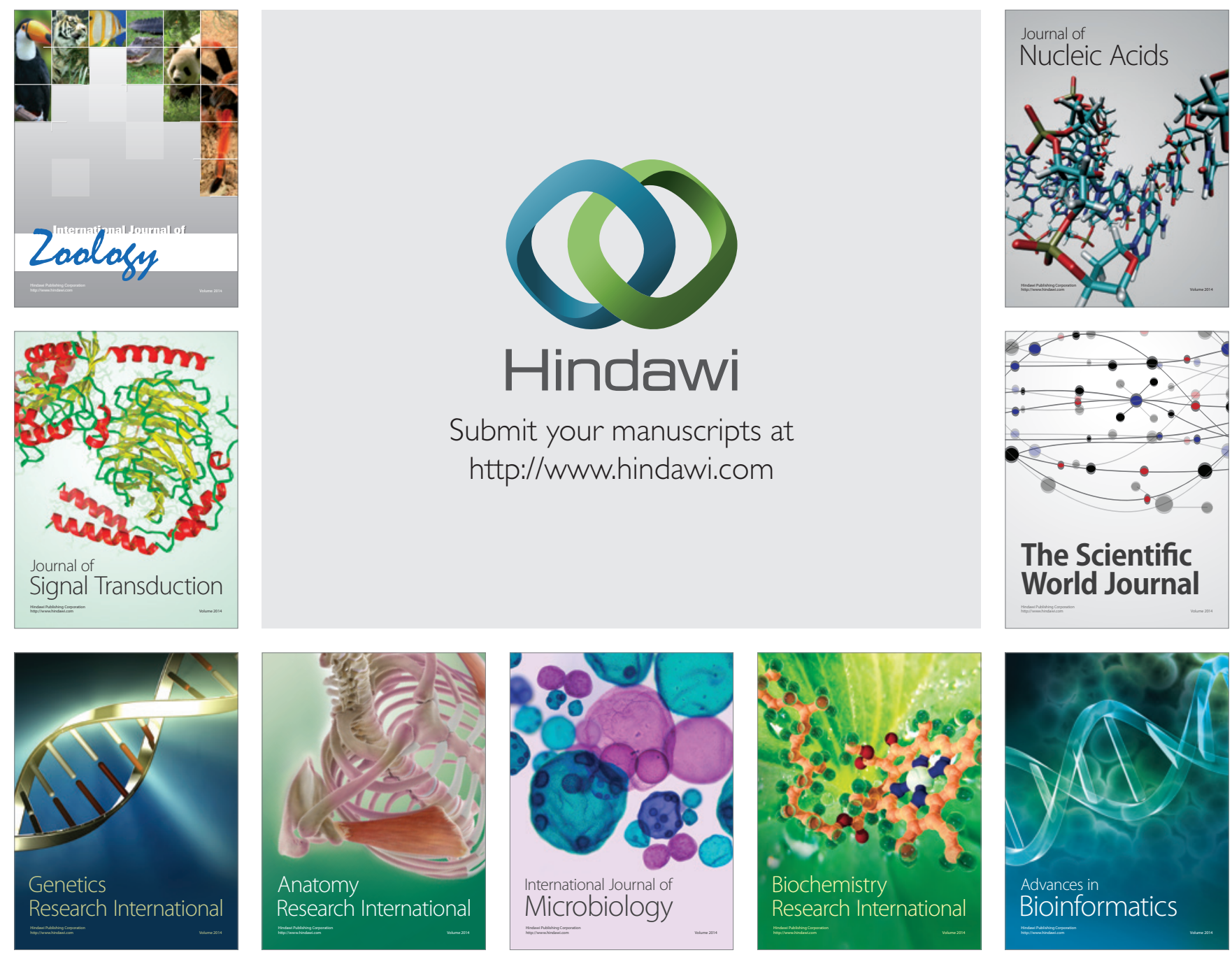

The Scientific World Journal
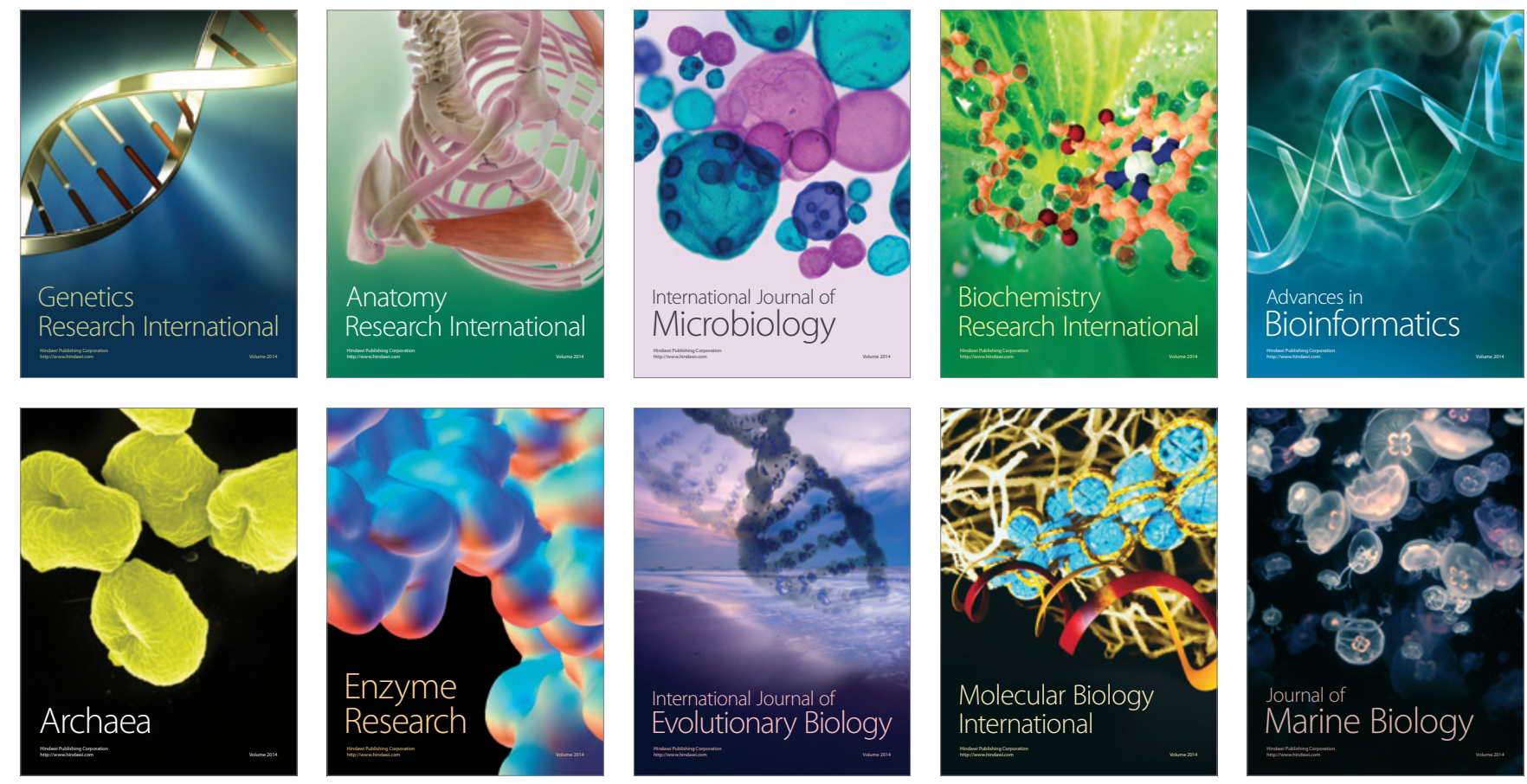